\title{
Single and Multiband UWB Circular Patch Antenna for Wireless Communication Applications
}

\author{
Raad H. Thaher \\ College of Engineering, Al-Mustansiryah University, Baghdad, Iraq
}

Email address:

Raadthaher55@gmail.com

To cite this article:

Raad H. Thaher. Single and Multiband UWB Circular Patch Antenna for Wireless Communication Applications. American Journal of Electromagnetics and Applications. Vol. 3, No. 3, 2015, pp. 16-23. doi: 10.11648/j.ajea.20150303.11

\begin{abstract}
This paper presents the design of an ultra-wide band (UWB) circular patch antenna with microstrip line feed and optimization of various antenna parameters. The antenna with dimension of $(33 \times 30 \times 1.5) \mathrm{mm}^{3}$ is fabricated on FR-4 epoxy substrate having permittivity constant $\boldsymbol{\varepsilon}_{\mathrm{r}}=4.3$, loss tangent $\tan \delta=0.002$. The designed antenna has the capability of operating in the bands (2.7-4) GHz, (6.8-12.5) GHz and (14.6-18) GHz. The antenna performance was modified by inserting a slot in the ground plane to achieve impedance bandwidth $\left(\mathrm{S}_{11}<-10 \mathrm{~dB}\right)$ in $(2.7-20) \mathrm{GHz}$. The modified antenna was fabricated and tested using the vector network analyzer. The simulated and measured results are presented and compared. The feed line used has characteristic impedance of $50 \Omega$.
\end{abstract}

Keywords: Microstrip Antenna, Standing Wave Ratio, Field Configuration, Circular Patch Antenna

\section{Introduction}

Antennas have importance in the field of wireless communication. Ultra wide band (UWB) communication systems allow high bandwidth reducing the multipath effect which may cause fading [1]. The Federal Communications Commissions (FCC) has approved the license-free UWB usage with in the frequency range $(3.1-10.6) \mathrm{GHz}$ and power spectral density of $-41.3 \mathrm{dBm} / \mathrm{MHz}$. Therefore the aim for both military and commercial applications is low cost UWB systems. One of the tasks is to realize effective UWB antenna that guarantee performance in term of radiation properties, impedance matching and group delay with in the band of interest.

The basic form of microstrip antennas consist of a conducting patch printed on a ground substrate has impedance bandwidth of (1-2) \%. With radiated patch on one side of a dielectric substrate which contain ground plane on the other side. The patch is placed above the ground plane, it is very thin and made of conducting material such as copper or gold. Microstrip antennas offer the advantages of light weight, low cost, thin profile, suitability to shaped surface, and easily integrated in system that can be used in mobile satellite communications, direct broadcast system (DBS), remote sensing, global positioning system (GPS), hyperthermia in addition to military applications[6-10].
The range of relative dielectric constant for substrates used for the design of microstrip patch antennas is $2.2 \leq \varepsilon_{\mathrm{r}} \leq 12$. However thicker substrate lower the permittivity and originates at discontinuities. The conducting patch take different shapes and may be square, triangular, rectangular, elliptical, thin strip or any other shape. In our research work the circular patch antenna was used for dual bands and single band in the ultra band range frequency. The circular patch antenna is shown in figure (1).

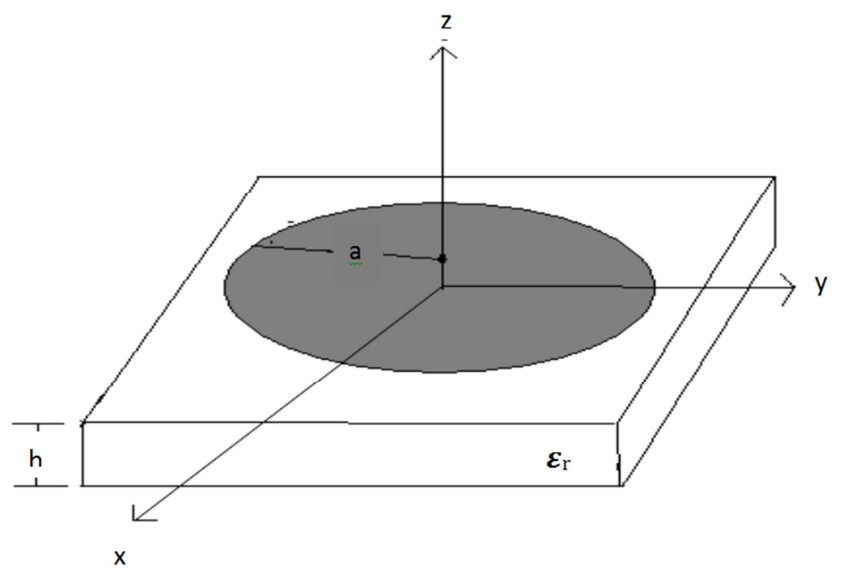

Figure (1). Circular patch antenna.

The directivity is a function of patch radius. The emitted 
radiation power increases with frequency. A microstrip antenna is made for a wide range of resonant frequencies polarization patterns and impedances and because of its operation features (i.e low power, high Q, very narrow bandwidth) it is used for mobile and security systems which require narrow bandwidth. They can also be used on microcomputers, mobile phones, laptops, etc.

There are three common models for the analysis of microstrip antennas, they are transmission line model, cavity model and full wave model. The transmission line model is the simplest and less accurate, the full wave model is the most complex and is very accurate. The time average pointing vector can be written as $[3,4]$

$$
\mathrm{S}_{\mathrm{av}}=\frac{1}{2} \operatorname{Re}[\mathrm{ExH}] \mathrm{W} / m^{2}
$$

where

$\mathrm{E}$ is the electric field $\mathrm{V} / \mathrm{m}$

$\mathrm{H}$ is the magnetic field $\mathrm{A} / \mathrm{m}$

The characteristic impedance can be expressed by [3].

$$
Z_{c}=\frac{120 \pi}{\sqrt{\varepsilon_{\text {reff }}}\left[\frac{W_{f}}{h}+1.393+0.667 \ln \left(\frac{W f}{h}+1.444\right)\right]}
$$

$\boldsymbol{\varepsilon}_{\text {reff }}$ is effective dielectric constant

wf is the feeder width

$\mathrm{h}$ is the height of the substrate

The aim of this research work is to design a circular microstrip antenna suitable for ultra wide band (UWB) frequencies. Practical and simulation measurement will be presented and compared for accuracy.

\section{Field Configuration of Circular Patch}

The modes supported by the circular patch antenna can be obtained by considering the patch, ground plane and the substrate between them as a circular cavity The modes of the antenna can be controlled by the radius of the patch [2]. The cavity model can be used to analyze the antenna. The vector potential can be used to find the field configuration with in the cavity. The magnetic vector potential Az must satisfy the homogenous wave equation [4]

$$
\mathrm{A}_{\mathrm{z}}(\psi, \varnothing, \mathrm{z})+\mathrm{K}^{2} \mathrm{~A}_{\mathrm{z}}(\psi, \varnothing, \mathrm{z})=0
$$

Whose solution can be written as

$$
A_{z}=-B_{m n p} J_{m}\left(K_{\rho} p^{-}\right)\left[A_{z} \cos \left(m \emptyset^{-}\right)+B_{z} \sin \left(n \emptyset^{-}\right)\right] \cos \left(K_{Z} Z^{-}\right)
$$

With constraint equation of

$$
\left(\mathrm{K}_{\rho}\right)^{2}+\left(\mathrm{K}_{\mathrm{z}}\right)^{2}=\omega_{\mathrm{r}}^{2} \mu \epsilon
$$

Therefore, the electric and magnetic fields can be expressed as

$$
\left.\begin{array}{c}
E \psi=-j \frac{1}{\omega \mu \epsilon} \frac{\partial^{2} A z z}{\partial \rho \mathrm{d} z}, H \psi=\frac{1}{\mu} \frac{1}{\rho} \frac{\partial A z}{\partial \emptyset} \\
E \emptyset=-j \frac{1}{\omega \mu \epsilon} \frac{1}{\rho} \frac{\partial^{2} A z}{\partial \rho \mathrm{d} z}, H \emptyset=-\frac{1}{\mu} \frac{\partial A z}{\partial \rho d x} \\
E z p=-j \frac{1}{\omega \mu \epsilon}\left(\frac{\partial^{2} A z}{\partial z^{2}}+K^{2} A z\right), H z=0
\end{array}\right\}
$$

And the resonant frequency for $\mathrm{TM}_{\mathrm{mno}}$ modes can be written as

$$
\begin{aligned}
& \left(\mathrm{f}_{\mathrm{r}}\right) \mathrm{mno}=\frac{1}{2 \pi \sqrt{\mu \epsilon}} \frac{\left(X m n^{-}\right)}{a}=\frac{1.814}{2 \pi a \sqrt{\mu \epsilon}} \\
& \boldsymbol{\varepsilon}_{\text {reff }}=\frac{\varepsilon_{r}+1}{2}+\frac{\varepsilon_{r}-1}{2}\left[1+\frac{12 h}{\omega}\right]
\end{aligned}
$$

Where

$\boldsymbol{\varepsilon}_{\mathrm{r}}$ is substrate dielectric constant $\omega$ is patch width

\section{The Proposed Antenna Configuration}

The proposed shape of the antenna is shown in figure (2) it consist of the feeder and disk with radii $\mathrm{r}_{1}, \mathrm{r}_{2}$ respectively.

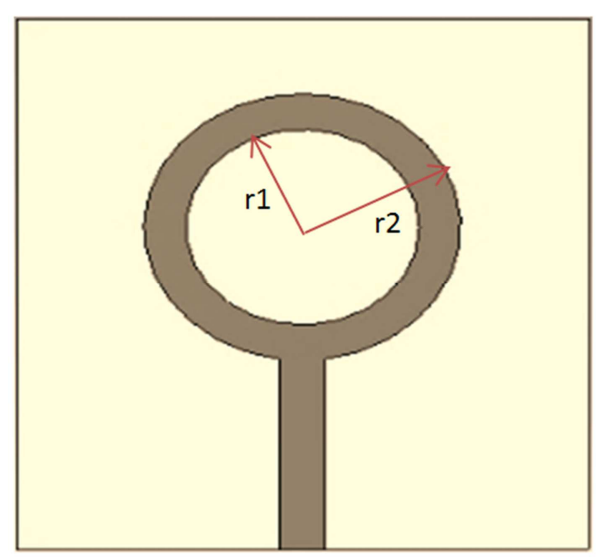

Figure (2). Proposed ring patch antenna.

Now we study the variation of the different parameters such as $\mathrm{r}_{1}, \mathrm{r}_{2}, \mathrm{l}_{\mathrm{f}}, \mathrm{w}_{\mathrm{f}}$ which are discussed below.

1. The effect of $r_{1}$

Figure (3) shows the effect of variation of $r_{1}$ it is clear that $\mathrm{r}_{1}=6 \mathrm{~mm}$ gives the best results.(i.e the reflection coefficient $\mathrm{s} 11<-10 \mathrm{~dB})$ for $(2.7-18) \mathrm{GHz}$.

2. The effect of $r_{2}$

Figure (4) shows the effects of $r_{2}$. It is shown that the $r_{2}=8 \mathrm{~mm}$ is the best for $(2.7-18) \mathrm{GHz}$.

3 . The effect of the feeder length $\left(l_{\mathrm{f}}\right)$

Figure (5) shows the effect of feeder length it is shown the $1_{\mathrm{f}}=12.2 \mathrm{~mm}$ is the best.

4. The effect of feeder width $\left(\mathrm{w}_{\mathrm{f}}\right)$

Figure (6) shows the effects of the feeder width it is shown that the $\mathrm{w}_{\mathrm{f}}=2.4 \mathrm{mmgive}$ the best result for $(2.7-18) \mathrm{GHz}$

5 . The effect of ground width $\mathrm{w}_{\mathrm{g}}$

Figure (7) shows the effect of $\left(\mathrm{w}_{\mathrm{g}}\right.$. It is noted that $\mathrm{w}_{\mathrm{g}}=14 \mathrm{~mm}$ gives better results for $(2.7-18) \mathrm{GHz}$

6 . The effect of ground length $1 \mathrm{~g}$

Figure (8) shows the effect of $\lg$.it is noted that $\mathrm{lg}=2.4 \mathrm{~mm}$ 
gives better results for (2.7-18)GHz.

It is observed that the proposed antenna give better value of $\mathrm{s}_{11}$ (i.e less than $-10 \mathrm{~dB}$ ) in the bands from $(2.7-4) \mathrm{GHz}$, (6.8-12.5) $\mathrm{GHz}$ and (14.6-18) $\mathrm{GHz}$.
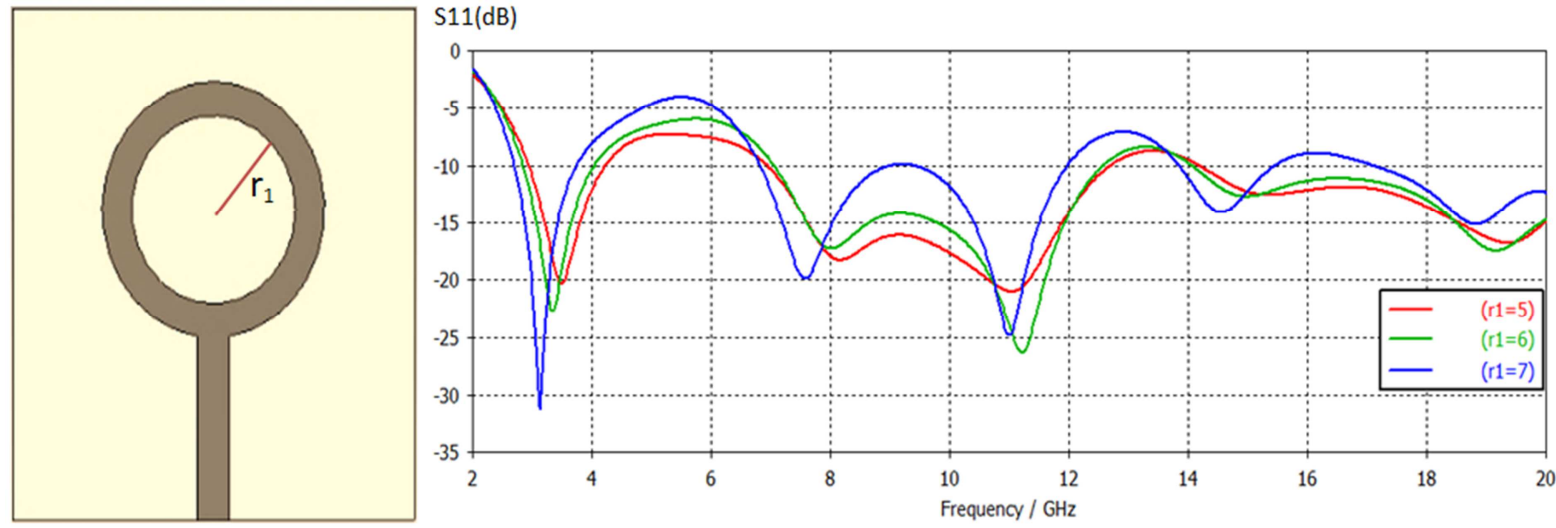

Figure (3). Effect of $r_{I}$.
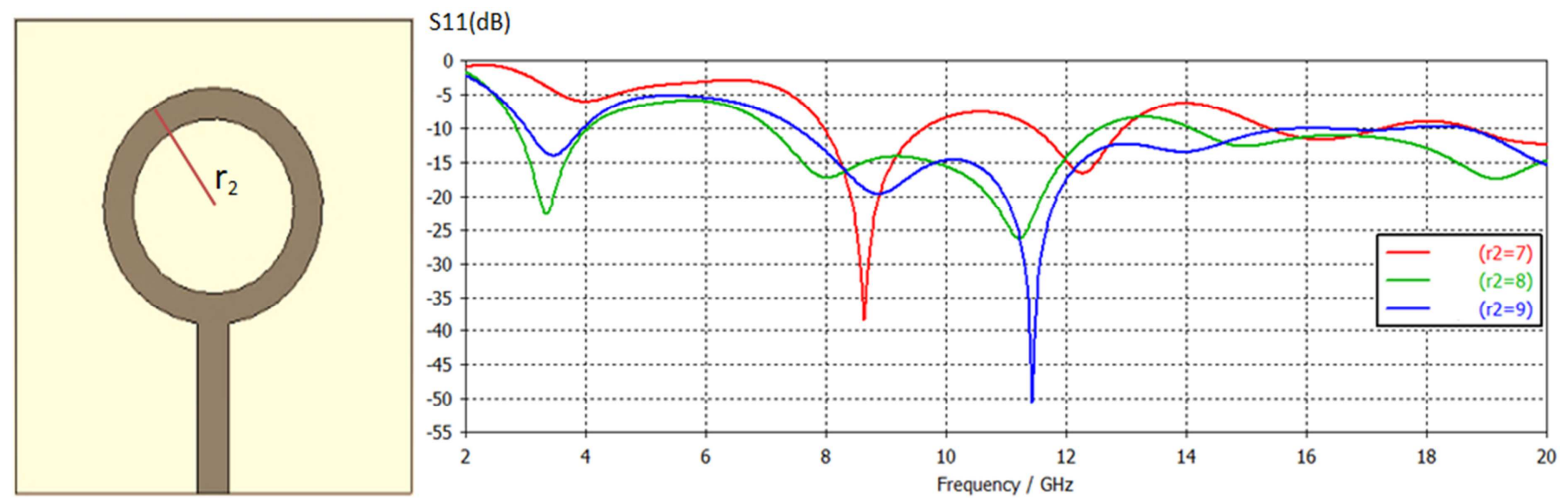

Figure (4). Effect of $r_{2}$.
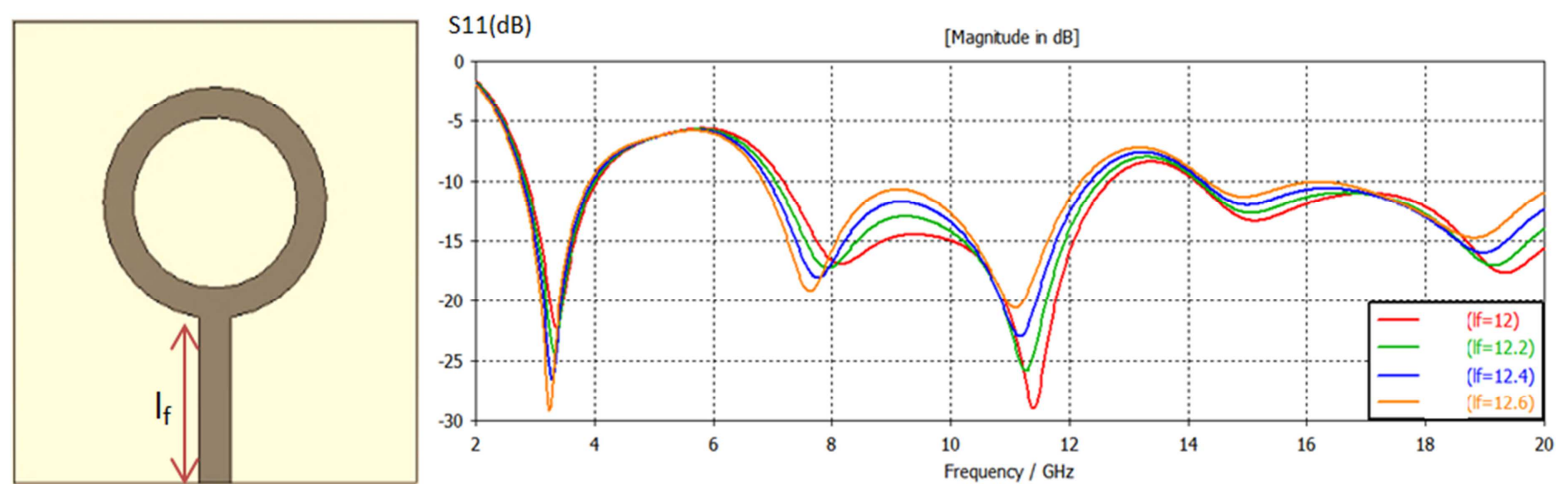

Figure (5). Effect of $l_{f}$.
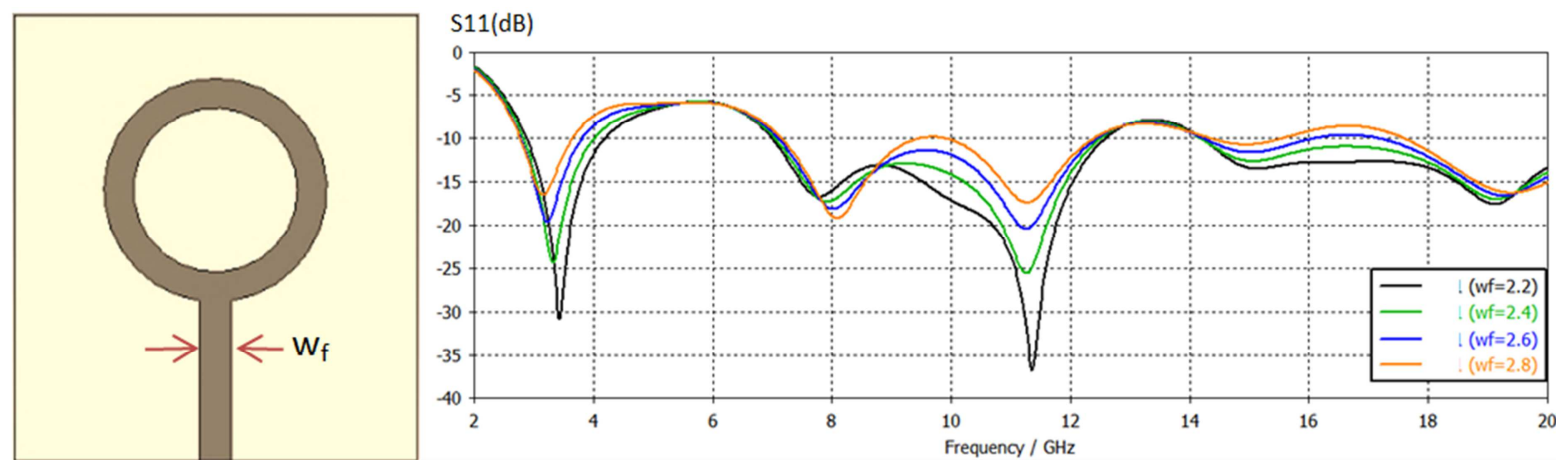

Figure (6). Effect of $w_{f}$ on the attenuation. 

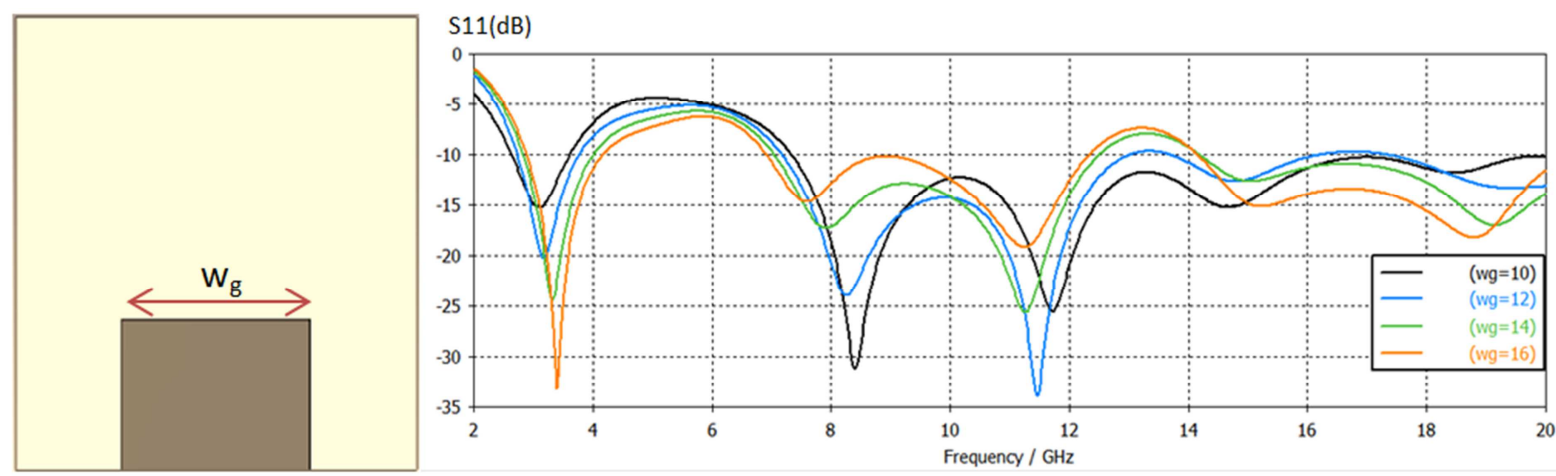

Figure (7). Effect of $w_{g}$ on the attenuation.
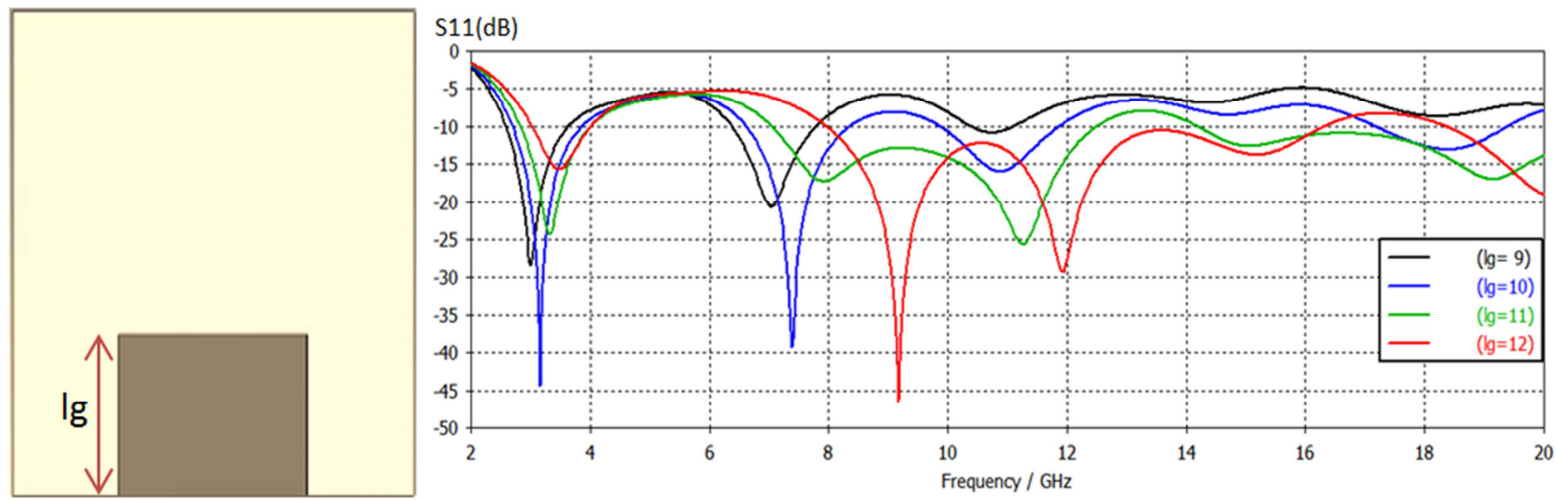

Figure (8). Effect of $l_{g}$ on the attenuation.

Therefore the antenna is modified to improve its characteristics by inserting another circle and making a slot in the ground plane as shown in figure (9).

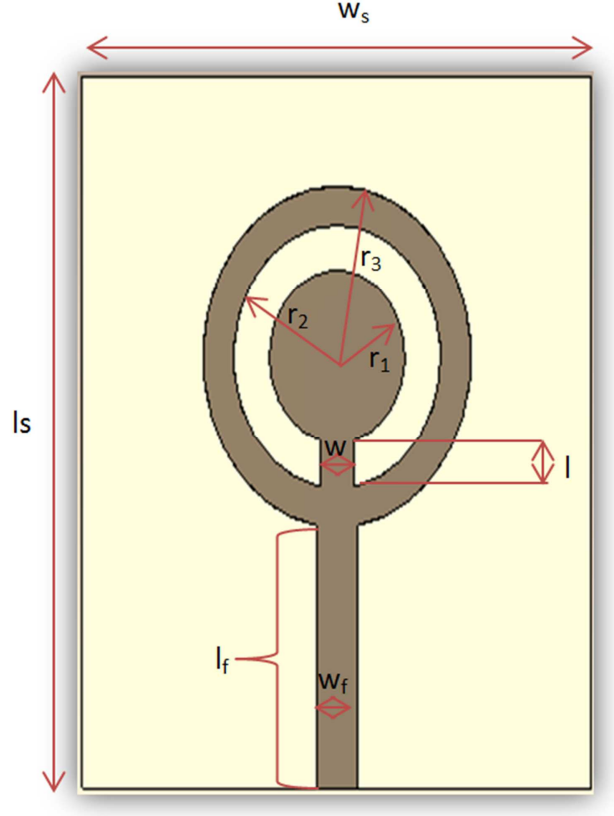

(a) front

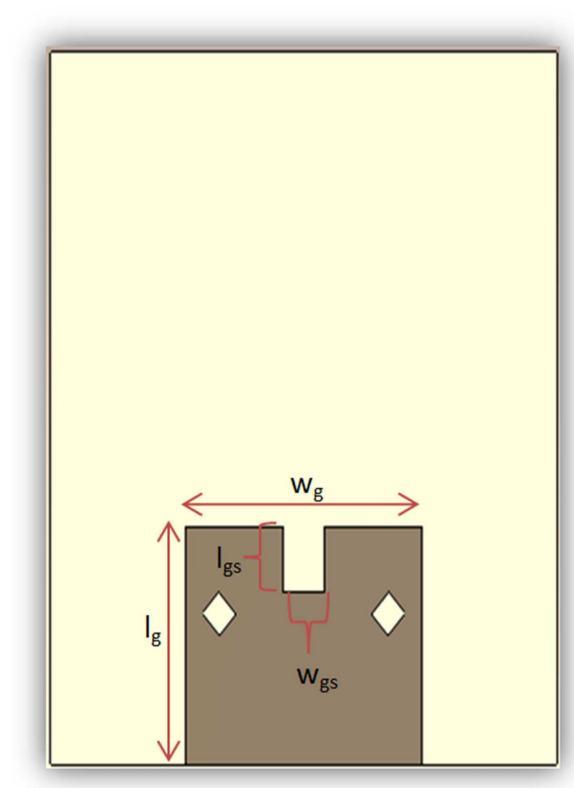

(b) back

Figure (9). The front and back faces modified antenna.

The effect of the other parameter such as $\mathrm{r}_{3}, \mathrm{w}, \mathrm{w}_{\mathrm{gs}}$ is shown in figures $10,11,12$ respectively, from these figures it can be noted that the characteristics of the antenna is improved by increasing the operating band (ie $\mathrm{S}_{11}<10 \mathrm{~dB}$ ) by adding a slot in the ground part. 

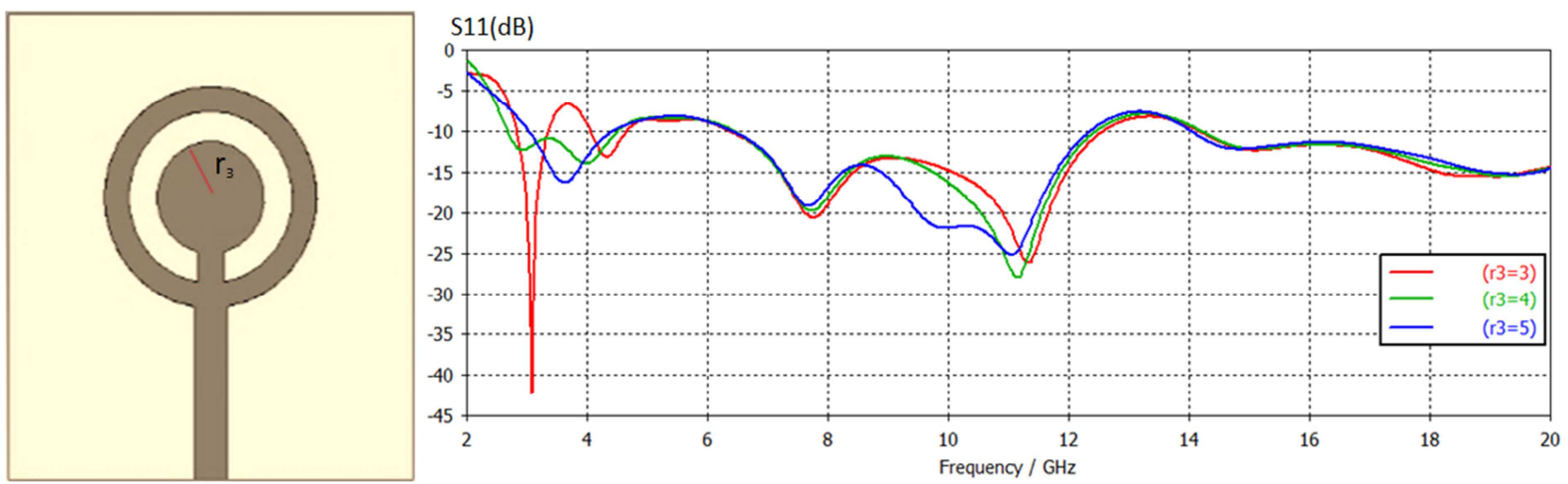

Figure (10). Add circle with effect $r_{3}$.
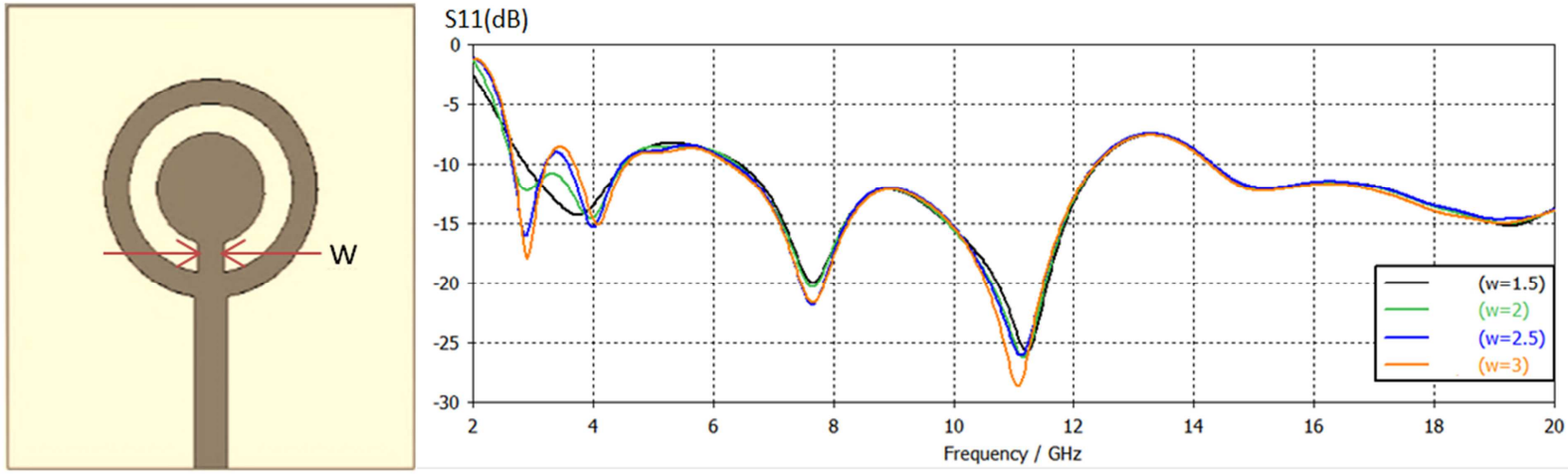

Figure (11). Effect of $w$.
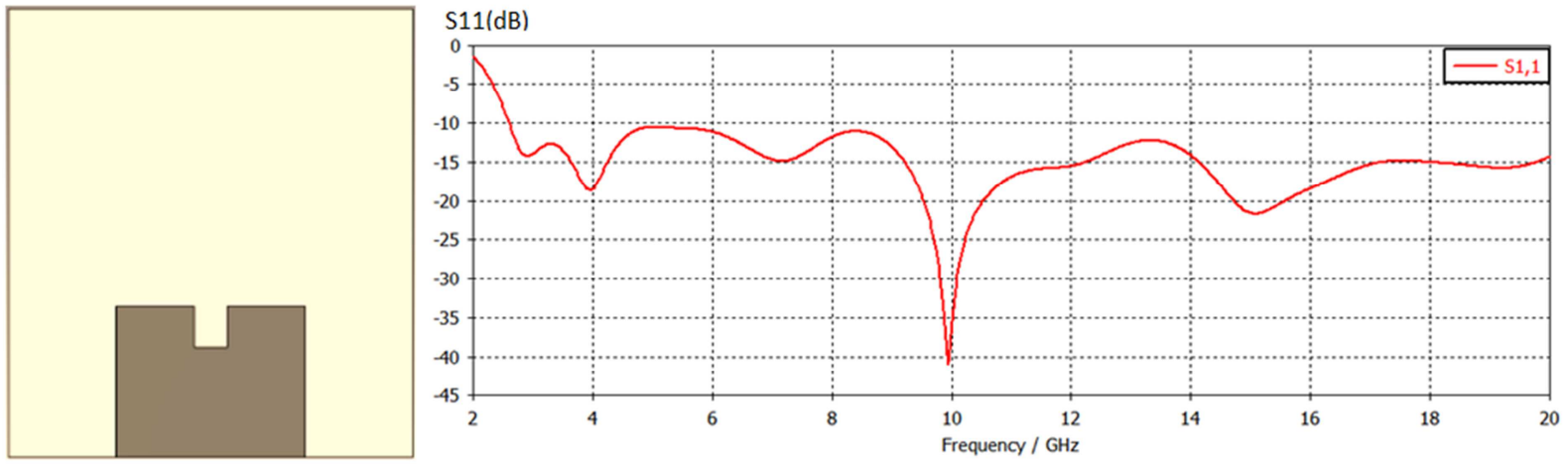

Figure (12). The effect of making slot in ground plane.

Therefore the modified antenna gives $S_{11}$ less than $-10 \mathrm{~dB}$ in the frequency band (2.7-20) GHz which is suitable for ultra wide band. Table (1) shows the appropriate parameters values of the modified antenna parameters.

Table (1). Design parameters of the modified proposed antenna.

\begin{tabular}{llll}
\hline parameter & Value $(\mathbf{m m})$ & parameter & Value $(\mathbf{m m})$ \\
\hline $\mathrm{ls}$ & 33 & $\mathrm{l}_{\mathrm{f}}$ & 12.2 \\
$\mathrm{~W}_{\mathrm{s}}$ & 30 & $\mathrm{~W}_{\mathrm{f}}$ & 2.4 \\
$\mathrm{r}_{1}$ & 4 & $\mathrm{l}_{\mathrm{g}}$ & 11 \\
$\mathrm{r}_{2}$ & 6.1 & $\mathrm{~W}_{\mathrm{g}}$ & 14 \\
$\mathrm{r}_{3}$ & 7.9 & $\mathrm{l}_{\mathrm{gs}}$ & 3 \\
$\mathrm{~L}$ & 2.127 & $\mathrm{w}_{\mathrm{gs}}$ & 1.2 \\
$\mathrm{~W}$ & 2 & $\mathrm{~h}$ & 1.5 \\
\hline
\end{tabular}

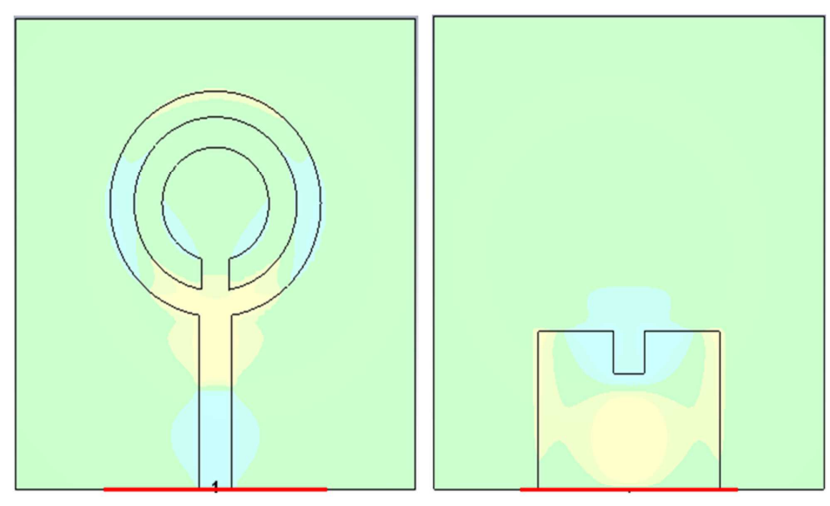

Figure (13). Current distribution.

However, the characteristics of the modified antenna such as the current distribution, voltage standing wave ratio (vswr) 
and radiation pattern are shown in figure $(13,14,15)$ respectively. The standing wave ratio can defined as the ratio of maximum voltage (electric field) to the minimum voltage (electric field) and can be considered as a measure of the degree of mismatch. The acceptable value of VSWR $<2$ in the transmission band required. The $3 \mathrm{D}$ view is shown in figure (16). In addition the modified antenna is fabricated and tested practically using the network vector analyzer and compared with the traditional values as shown in figure (17). It is noted that the antenna is tuned to $6.2 \mathrm{GHz}, 9.5 \mathrm{GHz}, 5.13 \mathrm{GHz}$ (minimum reflection coefficient) and the measured results agrees with the simulation results in the UWB region. The small difference is due to the relative dielectric constant variations. Figure (18) shows the photograph of the modified
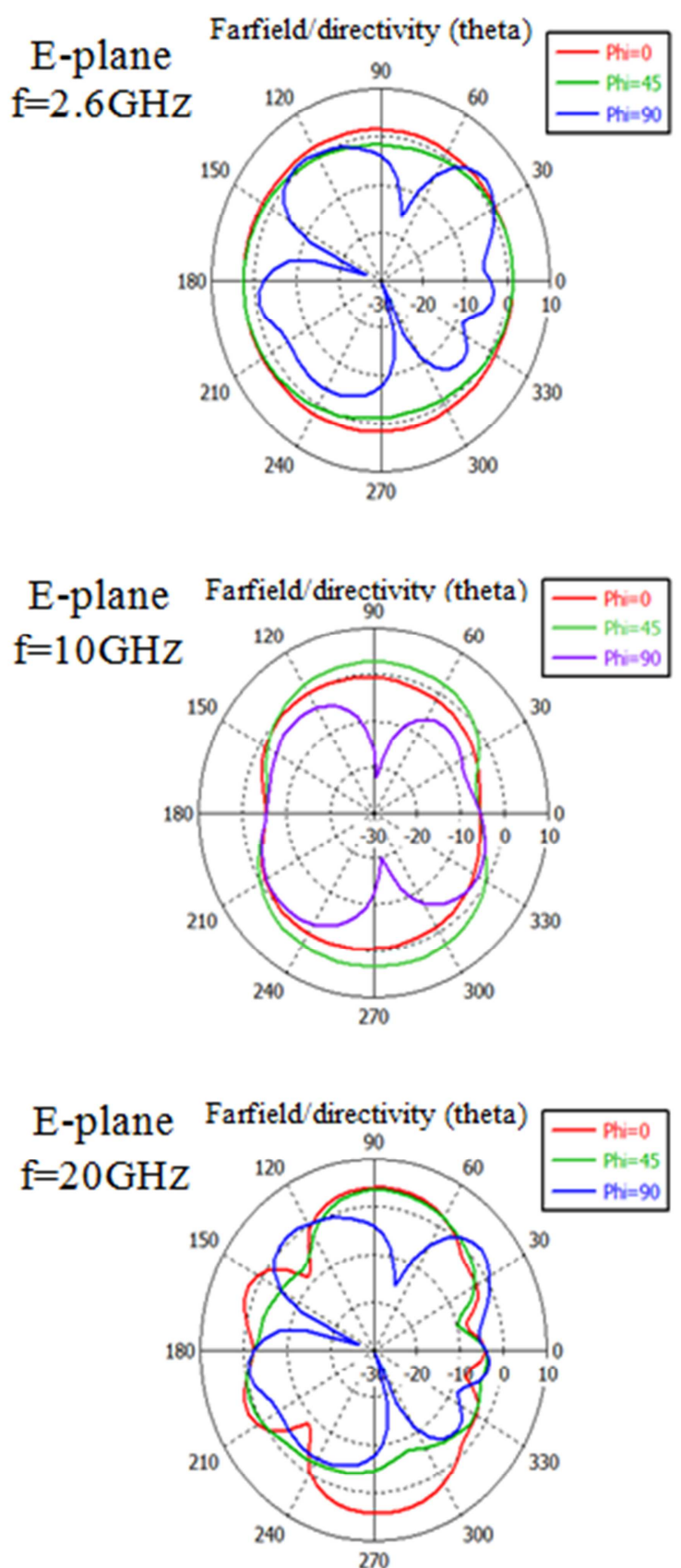

antenna.

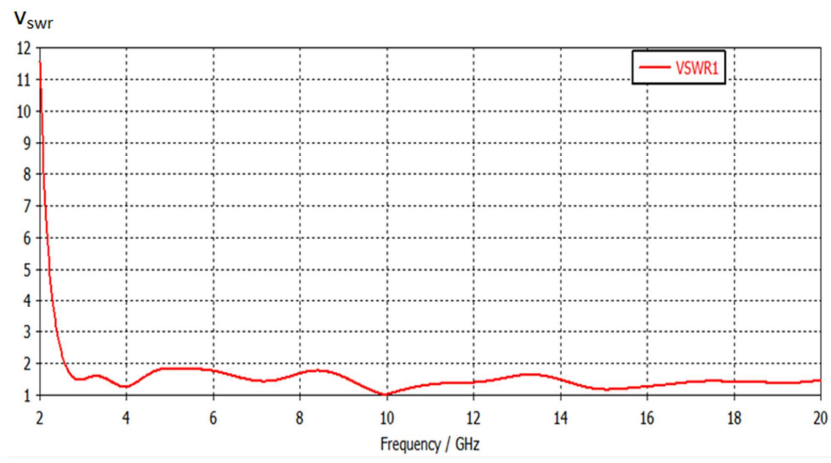

Figure (14). Voltage standing wave ratio.
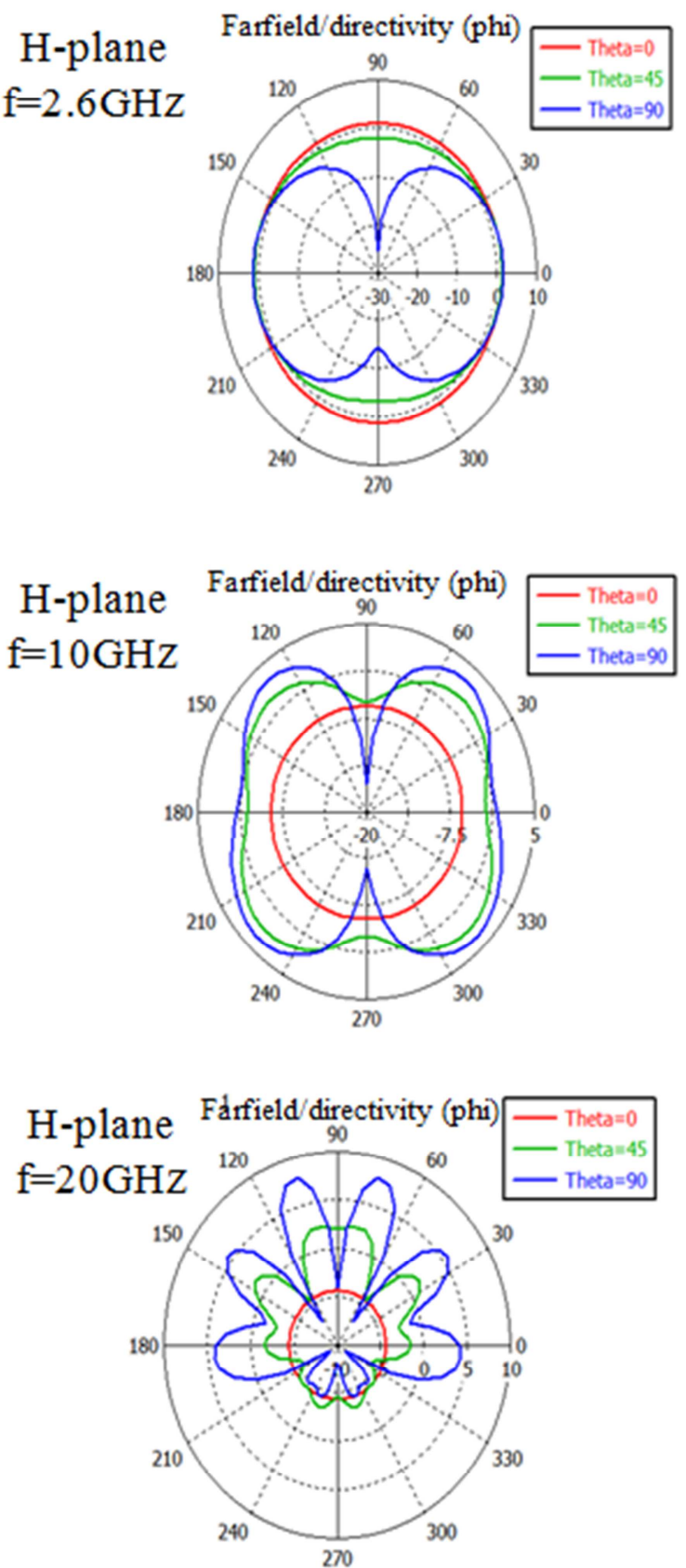

Figure (15). Far field Radiation Pattern for the amplitudes of electric and magnetic fields, emitted by the antena for three frequencies. 


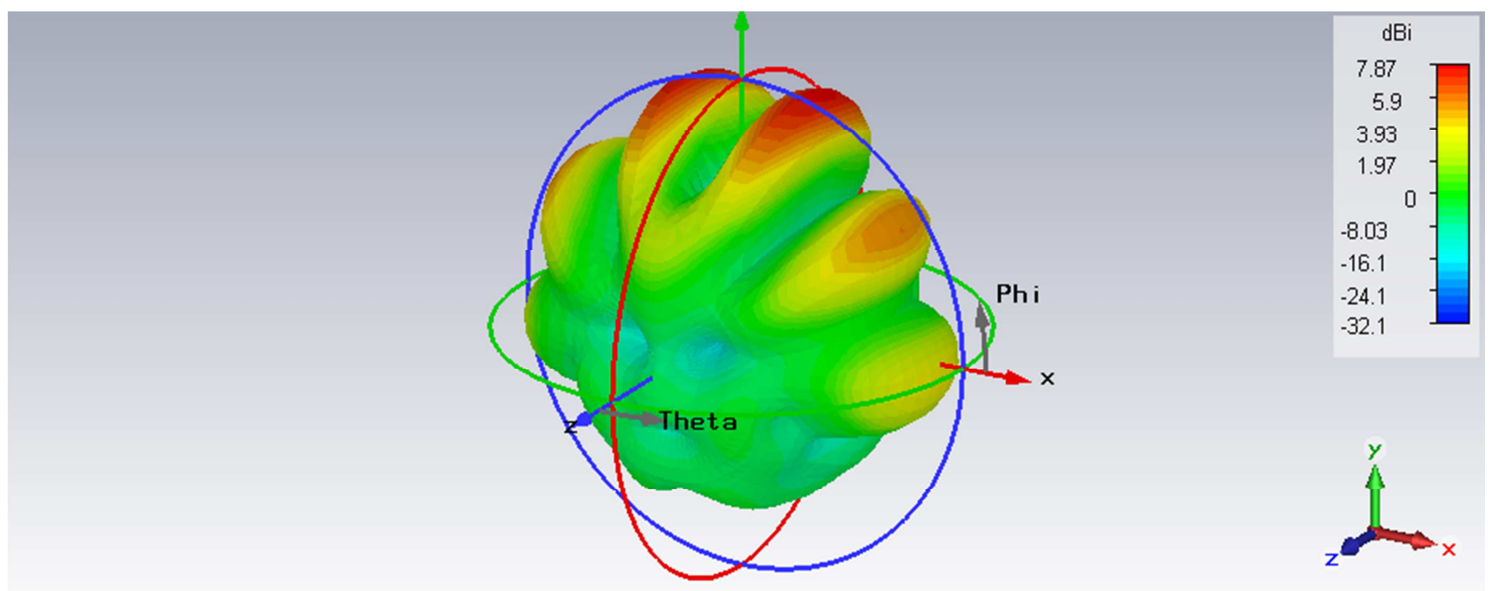

Figure (16). $3 D$ view of the proposed antenna.

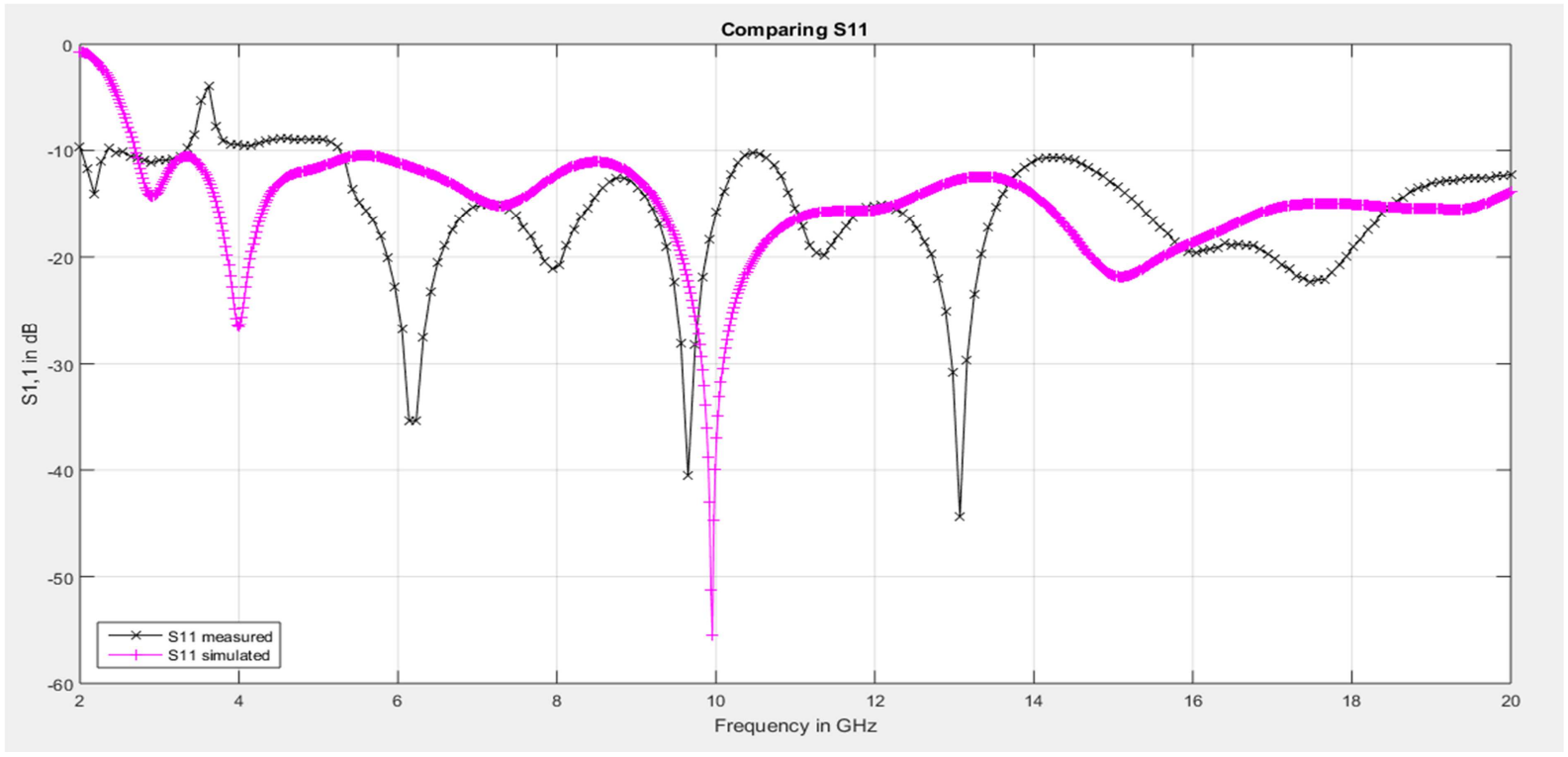

Figure (17). Measured and simulation of the attenuation versus frequency.
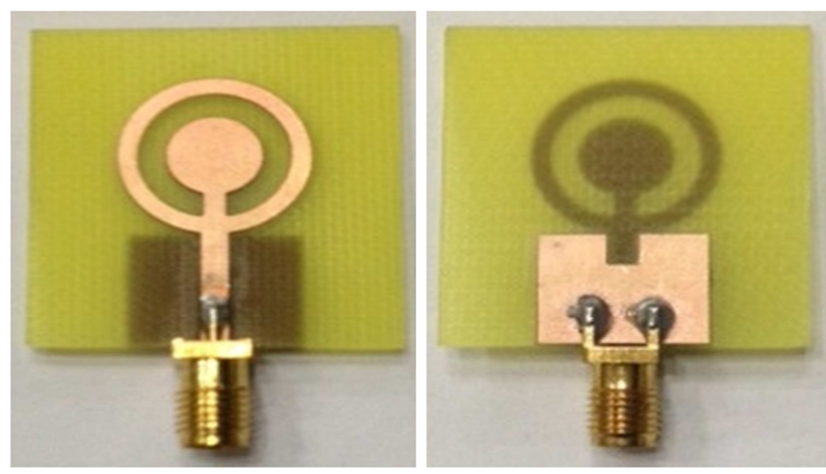

Figure (18). The top and bottom faces of the practical modified antenna.

\section{Conclusions}

The circular microstrip patch was designed and the effect of all parameters was studied and optimized. It was observed that the proposed antenna has three transmission bands in which the reflection coefficient is less than - 10dB which are (2.7-4)
$\mathrm{GHz},(6.8-12.5) \mathrm{GHz}$ and (14.6-18) GHz respectively. By inserting a slot in the ground plane it was found that the characteristics of the proposed antenna was improved so that the operating band become (2.7-20) GHz. The modified antenna was fabricated. The simulation results and practical results were presented and compared. It was found that the antenna parameters such as return loss and radiation pattern show reasonable agreement with simulated result. The antenna can find applications in radar and space craft application. The modified antenna has a compact size $(33 \times 30)$ $\mathrm{mm}^{2}$.

\section{References}

[1] Marjan Mokhtaari, Jens. Borneman" Directional ultra-wideband Antennas in planar technologies", Proceeding of the $8^{\text {th }}$ microwave conference, pp 885-888, 2008.

[2] B. J. Kwaha, O. N Inyang, P. Amalu, "The circular microstrip patch antenna - design and implementation," IJRRAS, vol 8, Issue 1, pp86-95, 2011. 
[3] C. A. Balanis, "Modern Antenna Handbook", John Wiley and Sons, 2008 .

[4] Gonca, Cakir. "Design simulation and tests of low-cost microstrip patch antenna arrays for the wireless communication", Turk J Elect Engin, 13 (1). 2005.

[5] 5. Richards W. F. "Antenna Handbook, Theory, Applications and Design”, Editors, Y. T. Lo, S. W. Lee, 1988.

[6] Debashish pal. "Design of an ultra wide- band fractal antenna for microwave applications", Internal Journal of Advanced Research in Electronics and Communication Engineering (IJARECE), volume 3, pp1302-1305, 2014.

[7] W. Mahar, M. A. Tahir, F. ABhatti."Compact patch antenna for ultra wide-band applications" PIERS Proceeding, Stockholm, Sweden, pp 1100-1104, 2013.

[8] Baskaran Kasi, Lee Ping, Chanden Chakrabarty."Acompact microstrip antenna for ultra wide-band applications" Europen Journal of Scientific Research, Vol 67, No.1, pp45-51, 2011.

[9] Swapnali Shinde, R. P. Labde, Design of a planar monopole ultra wide-band patch antenna" International Journal of Electrical and Electronics Engineering Research (IJEEER).Vol.4, pp47-52, 2014.

[10] Ajay Yadav, Atishya Malav." Microstip antenna with WIMAX notched band characteristics" International Journal of Recent Research and Review, Vol. VII, Issue 2, 2014. 